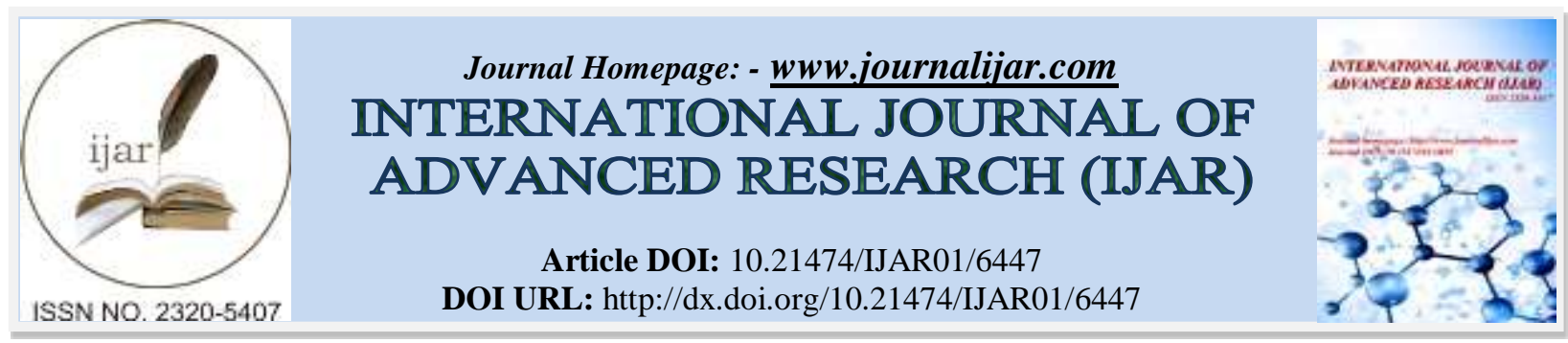

RESEARCH ARTICLE

\title{
STUDIES ON PHYSICAL PROPERTIES AND CHEMICAL MAKE-UP OF HYBRID AND NATIVE VARIETIES OF FLAXSEEDS.
}

Vanita S. Bhat ${ }^{1}$, Jayarama Naik $\mathbf{N}^{1}$ and "Basavaraj Madhusudhan ${ }^{2}$.

1. Department of Food Technology, Davangere University, Davangere - 577 007, Karnataka, India.

2. Research Center for Nanoscience and Technology, Department of Biochemistry and Food Technology, Davangere University, Shivagangothri, Davangere- 577007, Karnataka, India.

\section{Manuscript Info}

Manuscript History

Received: 05 December 2017

Final Accepted: 07 January 2018

Published: February 2018

\section{Key words:-}

Flaxseeds; NL-115 and LM-001

cultivars; physico-chemical properties, sensors.

\begin{abstract}
The present work reports the physical properties and chemical make-up of two flaxseeds cultivars NL-115 (hybrid) and LM-001 (native) of Indian origin. The flaxseeds cultivars exhibited variations in dimensions include length, width, thickness and diameter increase linearly with increase in moisture content. The retention of moisture by the seeds depends on their chemical constituents.The geometric properties increased as the moisture content increased. The bulk density, rupture force, deformation and energy absorbed decreased linearly while true density, porosity, thousand seed mass, angle of repose and static coefficient of friction increased linearly with increasing moisture content. The dimensional parameters such as length, width and thickness varied from 4.74 to $4.79 \mathrm{~mm}, 2.41$ to $2.47 \mathrm{~mm}$, and 0.98 to $1.10 \mathrm{~mm}$, respectively. While, bulk density, true density, porosity and thousand kernel weight found to vary in the range of 630.03 to $640.66 \mathrm{~kg} / \mathrm{m}^{3}$, 866.50 to $868.50 \mathrm{~kg} / \mathrm{m}^{3}, 26.23$ to $27.29 \%$ and 7.56 to $6.59 \mathrm{~g}$, respectively. The static coefficient of friction found to vary from 0.43 to 0.59 and angle of repose from $27^{0} .00^{1}$ to $27^{0} .55^{1}$. The flaxseed variety NL-115 was found to be slightly larger and cream colored than dark colored LM-001 in appearance.
\end{abstract}

Copy Right, IJAR, 2018,. All rights reserved.

Introduction:-

Flaxseed or linseed (Linum usitatissimum L.) is familiar to folks by agsi in the northern part of Karnataka in India. Flaxseed is grown mainly for fibre and oil, moderately for pharmaceutical and ornamental use (Coskuner, Y. et al., (2007)). Flaxseed has long history of use in India and partly being consumed at lower levels as flaxseed chutney in southern India due to its crisp and chewy texture, pleasant and nutty tastes (Faseehuddin Shakir, K. A. et al., (2007)). In recent days, the interest in flaxseed is being increased at an alarming rate from the food and pharma industries due to their bioactive compounds of therapeutic value (Reema, V. et al., (2017)). Exclusively, the high amount of alphalinolenic acid (50-60\%) in endosperm portion would allow the whole flaxseeds to find place in poultry rations and obtain omega-3-fatty acid enriched eggs as functional food for humans. The remarkable health benefits of high content of lignans in hull-fraction of flaxseed is of particular, current interest and that will be converted to the aglycone forms by the gut microfora for systemic absorption (Madhusudhan, B. (2009)). The flaxseed seed-coat (hull) adheres tightly to the embryo/endosperm. Dehulled seed (endosperm) would be lower in fibre and higher in oil and protein content, whereas the hull fraction is rich in lignans and fibres composed of soluble (8\%) and insoluble (6\%) 
fiber (( Madhusudhan, B. et al., (2000)). The optical properties of several varieties of flaxseed have been especially focused in the present investigation due to their colored pigments and anti-nutritional factors on the seed-coat of therapeutic importance (Coskuner, Y. et al., (2007)). Because of these reasons, understanding the physical properties consisting of geometrical, gravimetrical and frictional properties of flaxseeds is highly warranted to design equipments, especially seed hopper, conveyers, seed metering, handling, processing and dehulling devices.

\section{Materials and Methods:-}

Two flaxseeds cultivars of Indian origin, native flaxseeds (LM-001) procured from the local market of Ranebennur, Karnataka and the hybrid flaxseeds (NL-115) grown and authenticated at the University of Agricultural Sciences, Raichur, Karnataka, India. The University of Agricultural Sciences, Hebbal, Bangalore, Karnataka, India authenticated the seeds. The two flaxseeds cultivars NL-115 (hybrid) and LM-001 (native) were subjected to air classifier to remove the dirt, dust, lighter particles. Damaged seeds were manually cleaned and a portion of flaxseeds evaluated for physical and optical properties, and the remaining bulk seeds were kept in tightly sealed container under 40C for other analysis (Kalay, K. et al., (2017)).

\section{Physico-chemical characterization:}

The stored flaxseeds were allowed to attain room temperature. The moisture content was determined using standard method (AOAC (2000)). The statistical analysis for the data obtained in triplicate was evaluated and reported as mean. All the physical properties were determined at moisture level $8.69 \%$ (d.b.) for NL-115 and $6.38 \%$ (d.b.) for LM-001 varieties (Table 1.). To determine the average size of the seed from each variety, a sample of 100 seeds was randomly selected. Measurements of the three major perpendicular dimensions of the flaxseeds were carried out with a digital caliper to an accuracy of $0.01 \mathrm{~mm}$. The geometric mean diameter, $\mathrm{Dg}$ of the respective varieties of flaxseeds was calculated by using the formula $\mathrm{Dg}=(\mathrm{LWT}) 1 / 3$ where, $\mathrm{L}$ is the length, $\mathrm{W}$ is the width and $\mathrm{T}$ is the thickness. Thousand seed weight was determined by counting 100 seeds and weighing them in an electronic balance and then multiplied by10 to give the mass of 1000 flaxseeds (Table 2.).

Table 1:- Percent Chemical make-up of flaxseeds NL-115 and LM-001 varieties ${ }^{\mathrm{a}}$

\begin{tabular}{|l|l|l|}
\hline Compounds (\%) & NL-115 & LM-001 \\
\hline Carbohydrate & $27.60 \pm 0.5$ & $30.00 \pm 0.2$ \\
\hline Protein(\% N x 6.25) & $19.74 \pm 0.2$ & $21.08 \pm 0.1$ \\
\hline Fat & $16.20 \pm 0.2$ & $22.01 \pm 0.2$ \\
\hline Moisture & $08.69 \pm 0.1$ & $06.38 \pm 0.3$ \\
\hline Ash & $03.54 \pm 0.3$ & $03.49 \pm 0.2$ \\
\hline
\end{tabular}

avalues are means $\pm \mathrm{SD}(n=3$ and $p<0.05)$

Table 2:- Physical and optical characteristics of flaxseeds NL-115 and LM-001 varieties

\begin{tabular}{|l|l|l|}
\hline Parameters & NL-115 & LM-001 \\
\hline Colour & Cream-Brown & Brownish black \\
\hline $\begin{array}{l}\text { Size, } \mathrm{mm} \\
\text { (Length, Width, Thickness) }\end{array}$ & $4.79,2.41,1.10$ & $4.74,2.47,0.98$ \\
\hline Volume, $\mathrm{g} / \mathrm{cm}^{3}$ & 000.87 & 000.87 \\
\hline Bulk Density, $\mathrm{kg} / \mathrm{m}^{3}$ & 640.66 & 630.03 \\
\hline Total Density, $\mathrm{kg} / \mathrm{m}^{3}$ & 868.50 & 866.50 \\
\hline Porosity, $\%$ & 026.23 & 027.29 \\
\hline $\begin{array}{l}\text { Coefficient of friction } \\
\text { (Wood, Metal, Glass) }\end{array}$ & $0.4478,0.4704,0.4394$ & $0.4878,0.5970,0.4540$ \\
\hline Angle of repose, degree & $27^{0} 00^{1}$ & \\
\hline 1000 seed weight, g & 7.56 & $27^{0} 55^{1}$ \\
\hline
\end{tabular}

Bulk density and particle density are important factors in designing of storage structures. Bulk density was determined by filling a $1000 \mathrm{ml}$ container with flaxseeds from a height of about $15 \mathrm{~cm}$, striking the top level and then weighing the contents. The true density defined as the ratio of mass of sample to its seed volume, was determined using the water displacement method. $50 \mathrm{ml}$ of water was placed in a $100 \mathrm{ml}$ graduated measuring cylinder and $5 \mathrm{~g}$ seeds were immersed. The amount of displaced water was recorded from the graduated scale of the cylinder. The 
ratio of weight of seeds to the volume of displaced water gave the true density. The porosity is the fraction of the space in the bulk grain which is not occupied by the grain. The porosity $(\varepsilon)$ of the bulk seed was calculated from the values of true density $\left(\rho_{t}\right)$ and bulk density $\left(\rho_{b}\right)$ using the relationship, given by Mohsenin (9).

$$
\varepsilon=\frac{\rho_{\mathrm{t}}-\rho_{\mathrm{b}}}{\rho_{\mathrm{t}}} \mathrm{X} 100
$$

The coefficient of static friction was determined using plywood, galvanized iron, aluminum, stainless steel, Kraft paper and polypropylene knitted bags. These are the common material used for transportation, storage and handling operations of grains. In this experiment, a hollow metal cylinder with $50 \mathrm{~mm}$ diameter and $50 \mathrm{~mm}$ high and open at both the ends was filled with seeds at the predetermined moisture content and placed on an adjustable tilting table such that the metal cylinder does not touch the table surface. The tilting surface was raised gradually by means of a screw device until the cylinder with seeds just starts to slide down. The angle of the surface was read from a scale and the static coefficient of friction was taken as the tangent of this angle.

To determine the dynamic angle of repose, $\theta$ a plywood box measuring $300 \mathrm{~mm} \times 300 \mathrm{~mm} \times 300 \mathrm{~mm}$, having a removable front panel was used. The box was filled with the seeds at the predetermined moisture content, and the front panel was quickly removed, allowing the seeds to flow to their natural slope. The angle of repose was calculated from measurements of seed free surface depths at the end of the box and the midway along the sloped surface and horizontal distance from the end of the box to this midpoint. All the experiments were replicated five times for each flaxseed samples and the average values were reported.

\section{Physical and optical characterization:-}

The size of flaxseeds is important in designing and developing grading, dehulling and sorting machineries for the separation of foreign material and thermal processing calculations. The particle size analysis of cleaned flaxseeds was determined through the developed image analysis technique (Prasad, K. (2012)). The procedure for the determination of dimensional properties (Length, L; Width, W; Thickness, T; Aspect ratio, AR; Surface area, SA; Geometric mean diameter, GMD), gravimetric properties (Bulk density, BD; True density, TD; Porosity, POR; Thousand kernel weight, TKW), the frictional properties (Angle of repose, AOR; Coefficient of friction on glass surface, CFG; Coefficient of friction on galvanized iron surface, CFGI; Coefficient of friction on plywood parallel surface, CFPP; Coefficient of friction on plywood perpendicular surface, CFPV) and optical properties like colour difference were adopted (Singh, Y. et al., (2013), Prasad, K. et al., (2010)). The moisture content was determined using standard method (AOAC (2000)). The statistical analysis for the data obtained in triplicate was evaluated and reported as mean.

\section{Statistical analysis:-}

The data from three replicates were processed by one-way ANOVA using the least significant test to determine the level of significance at $\mathrm{P}<0.05$. Regression analysis was carried out using Microsoft Excel-2003 software.

\section{Results and Discussion:-}

The moisture retention capacity of seeds is depends on their chemical constituents such as carbohydrates, proteins, lipids and others. The chemical properties of flaxseeds varieties are presented in Table 1. At the initial moisture content of NL-115 and LM-001 was $8.69 \%$ and $6.38 \%$ on d.b., respectively. The carbohydrate ranged between 27.60 $-30.00 \%$, Protein 19.74 to $21.08 \%$, fat 16.20 to $22.01 \%$ and ash content 3.54 to $3.49 \%$, for NL -115 and LM-001 varieties. The results slightly varied compare to the reports of other investigators (Gopalan, C. et al., (2007), Mazza, G. (2008)).

The study of physical, chemical and mechanical properties of food grain is important and essential in the design of processing machines, storage structures and processes. The shape and size of grains are important in the design and development of grading and sorting machineries for the separation of foreign material as well as for the thermal processing calculations. The data related to frictional characteristics with optical properties of NL-115 and LM-001 varieties grown in India (Table.2). 


\section{Dimensional properties:}

Determination of dimensional properties is important as the moisture content plays a very important role in bulk density, true density and porosity. On increasing moisture, dimensional values increase for both seed and kernel. Bulk density, true density and porosity are normally higher for kernel as compared to seed. The length of two different flaxseeds varieties under investigation varied from $4.74 \mathrm{~mm}$ (LM-001) to $4.79 \mathrm{~mm}$ (NL-115). The width of flaxseeds decreased from $2.47 \mathrm{~mm}$ (LM-001) to $2.41 \mathrm{~mm}$ (NL-115) as thickness (Table 2). The true density increased with moisture content from 866.50 to $868.50 \mathrm{~kg} / \mathrm{m} 3$ while bulk density decreased 640.66 to $630.03 \mathrm{~kg} / \mathrm{m} 3$. The obtained results are very well in agreement with earlier studies (Coskuner, Y. et al., (2007)).

The static coefficient of friction studied on three different surfaces (wood, metal, glass) is reported in Table 2. It ranged from 0.4394 to 0.5970 for NL-115 and LM-001 flaxseeds. NL-115 variety showed least coefficient of friction on both plywood, metal and glass surfaces. The LM-001 variety revealed the highest coefficient of friction on metal surface. The angle of repose of the studied raw flaxseeds varieties ranged from 270001 to 270551 (Table 2). The NL-115 variety showed least value of angle of repose than LM-001 variety. The obtained data may thus be used in the development of storage, conveying, processing, handling and transportation equipments.

\section{Optical properties:}

The lowest and highest values for lightness (L) were found among LM-001variety and NL-115 variety. Lightness shows degree of lightness to darkness in which NL-115 lightest variety with its off white to cream colored appearance than that of LM-001variety darkest as per colour difference. Therefore, the optical parameters thus may be considered to identify the variety on optical method, even online process could also be applied in sort of flaxseeds.

\section{Conclusions:-}

In the present study, certain variations were found in the observed physical and chemical properties of two Indian flaxseeds varieties. At the moisture content 8.69 and $6.38 \%$ d.b., the values of protein, fat and carbohydrates of flaxseeds NL-115 and LM-001varieties were 19.74 and 21.08\%; 16.20 and 22.01\%, and 27.60 and $30.00 \%$, respectively. The average length, width, thickness of flaxseeds NL-115 and LM-001varieties increased linearly with increasing moisture content. True density, porosity and angle of repose increased linearly whereas bulk density decreased linearly with increasing moisture content. The coefficients of static friction increased linearly plywood, metal and glass surfaces as the moisture content increased. The data obtained may provide helpful clues to develop automated sensors based equipments to be used in transportation, seed box handling, designing of belt conveyors, screw conveyors chutes, seed metering device in processing, pneumatic and storage purposes. Therefore, the different fractions of flaxseeds maybe recognized based on their contributing physico-chemical factors. The development of automated sensors in the system to identify the minute differences in physical, chemical and optical parameters using nanotechnological tools is highly needed for demanding industrial and field applications.

\section{Acknowledgements:-}

The authors wish to thank Mr. B.V. Satyendra Rao, Dept. of Grain Science and Technology, CFTRI, Mysore, India, for help with dehulling of flaxseeds. The financial assistance received from DST-SERB, Govt. of India, New Delhi (sponsored project Grant No SB/EMEQ-429/2014) for providing JRF \& SRF is duly acknowledged. Thanks are also to Davangere University, Karnataka, for facilities and encouragement. 


\section{References:-}

1. AOAC (2000): Approved methods of analysis. The Association of Official Analytical Chemists., WashingtonDC.

2. Coskuner, Y., Karababa, E. (2007): Some Physical Properties of Flaxseed (Linum Usitatissimum L.). Journal of Food Engineering., 78:1067-1073.

3. Coskuner, Y., Karababa, E. (2007): Physical Properties of Coriander Seeds (Coriandrum sativum L.). Journal of Food Engineering., 80: 408-416.

4. Faseehuddin Shakir, K.A., Madhusudhan, B. (2007): Hypocholesterolemic and hepatoprotective effects of flaxseed chutney: Evidence from animal studies. Indian J Clin Biochem., 22(1):117-121.

5. Gopalan, C., Ramasastri, B.V., Subramanian, S.C. (2007): Nutritive Value of Indian Food. National Inst. Nutrition (ICMR) Press., Hyderabad, India.

6. Kalay, K., Moses S. C., Ashok Kumar., Devesh Kumar., Abhishek Upadhyay. (2017): Physical Properties of Pigeon Pea Grains at Different Moisture Content. Int. J. Pure App. Biosci., 5(2): 556-562.

7. Madhusudhan, B., Wiesenborn, D., Schwartz, J., Tostenson, K., Gillespie, J. (2000): A dry mechanical method for concentrating the lignan secoisolariciresinol diglycoside in flaxseed. Lebensmittel-Wissenschaft undTechnologie., 33: 268-275.

8. Madhusudhan, B. (2009): Potential benefits of flaxseed in health and disease-A perspective. Agriculturae Conspectus Scientificus., 74(2):67-72.

9. Mazza, G. (2008): Production, processing and uses of Canadian flax. Proc. $1^{\text {st }}$ Int. Workshop CGNA, August 3 -6, Temuco, Chile.

10. Mohsenin, N. N. (1970): Physical Properties of Plant and Animal Materials. Gordon and Breach Science Publishers., New York.

11. Prasad, K., Vairagar, P.R., Bera, M. B. (2010): Temperature dependent hydration kinetics of Cicer arietinum splits. Food Research International., 43(2):483-488.

12. Prasad, K., Singh, Y., Anil, A. (2012): Effects of grinding methods on the characteristics of Pusa 1121 rice flour. Journal of Tropical Agriculture and Food Science., 40(2): 193-201.

13. Reema, V., Ranu Prasad., Alka Gupta. (2017):Functional Properties and Health Benefits in Flaxseed fiber and oil (Linum usitatissimum L.). International Journal of Home Science., 3(1): 368-369.

14. Singh, Y., Prasad, K. (2013): Physical characteristics of some of the paddy varieties as affected by shelling and milling. Oryza., 50(2): 174-180. 